
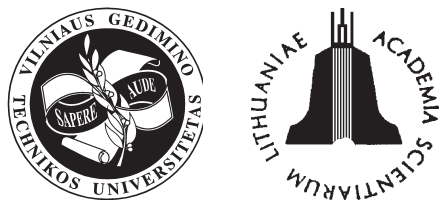

ISSN 1648-4142 print / ISSN 1648-3480 online TRANSPORT

www.transport.vtu.lt

\title{
INTERNAL NOISE MODELLING PROBLEMS OF TRANSPORT POWER EQUIPMENT
}

\author{
Jonas Bazaras \\ Dept of Transport Engineering, Kaunas University of Technology, Kęstučio g. 27, LT-44025 Kaunas, \\ Lithuania.E-mail:JonasB1@one.lt \\ Received 12 November 2005; accepted 4 January 2006
}

\begin{abstract}
The acoustic analysis of transport vehicles is presented in this article. Two types of vehicles of Russian production (TEP-60 and M62) were selected for this research. Using ANSYS/Multiphysic software acoustic noise of different power units in the engine sector was simulated. In this paper we present the modelling results of the locomotive internal noise. In ANSYS/Multiphysic anbience the problems of acoustics are solved on the basis of harmonic response analysis by providing harmonic pressure excitation (sine type) at some points of fluid structure and obtaining the pressure distribution in the fluid. By changing the agitation frequency variable sound distribution at the interval of different frequencies is obtained. Constructing the calculation scheme for a three dimensional locomotive model, spatial structure of finite elements is used. The whole construction was described by 3D finite elements FLUID30 designed for a specified acoustic analysis. The presented acoustic calculation model of rolling-stock cabin allows the evaluation of structural solutions and, in case of emergency, taking extra measures in the process of rolling-stock design. The results of acoustic calculation were compared with experimental measurements.
\end{abstract}

Keywords: noise, locomotive, damping parameters, internal space, acoustic.

\section{Introduction}

Commission of the EU has in recent years intensified its activities within noise abatement. Noise pollution is an increasing nuisance within the EU member states in an attempt to pursue measures against noise problem in the EU. If the noise limits are exceeded, several major factors are considered. The condition of rail and wheels, the type of trains, but it is certainly also a question of specific prediction method used. The prediction methods differ in many ways around Europe.

Noise transmission in locomotives can be difficult to study due to the complexity of the locomotives structure, difficulties in characterizing the excitation or describing the response. Earlier work has shown that structural vibration transmission can be predicted fairly accurately using a statistical energy analysis.

At high frequencies engine noise can be a problem in locomotives. Fan noise, combustion events, power train vibration, road wheel noise and aerodynamic noise can also input power to vehicle structure at frequencies above $250 \mathrm{~Hz}$, and at these frequencies statistical energy analysis can be used to study noise transmission [1-4].
Our objective was to analyze the internal noise pollution in the existing locomotives in Lithuania today. Speeds of trains are not high and at low speeds the locomotive noise is a dominating source. We have chosen two types of locomotives - freight locomotive M62 and passenger locomotive TEP60. In this paper we present the modelling results of these locomotives internal noise.

\section{Theoretical analysis}

Functional scheme of the existing harmful factors to human health in railway transport is presented in Fig 1.

Legislation norms for noise levels of the rolling stocks are defined in the standards. In Lithuania noise of the rolling stocks is reglamented by requisition No 692 of Minister of Health of Lithuanian Republic. Equivalent noise levels in working places in railway transport are defined in this requisition (Table 1) [5, 6].

Noise sources in the locomotive are grouped into three groups:

I - the noise rising in the motion devices -shoes, axle boxes with roller bearings, brake lever, traction engine, traction reducers and axle-wheels. 


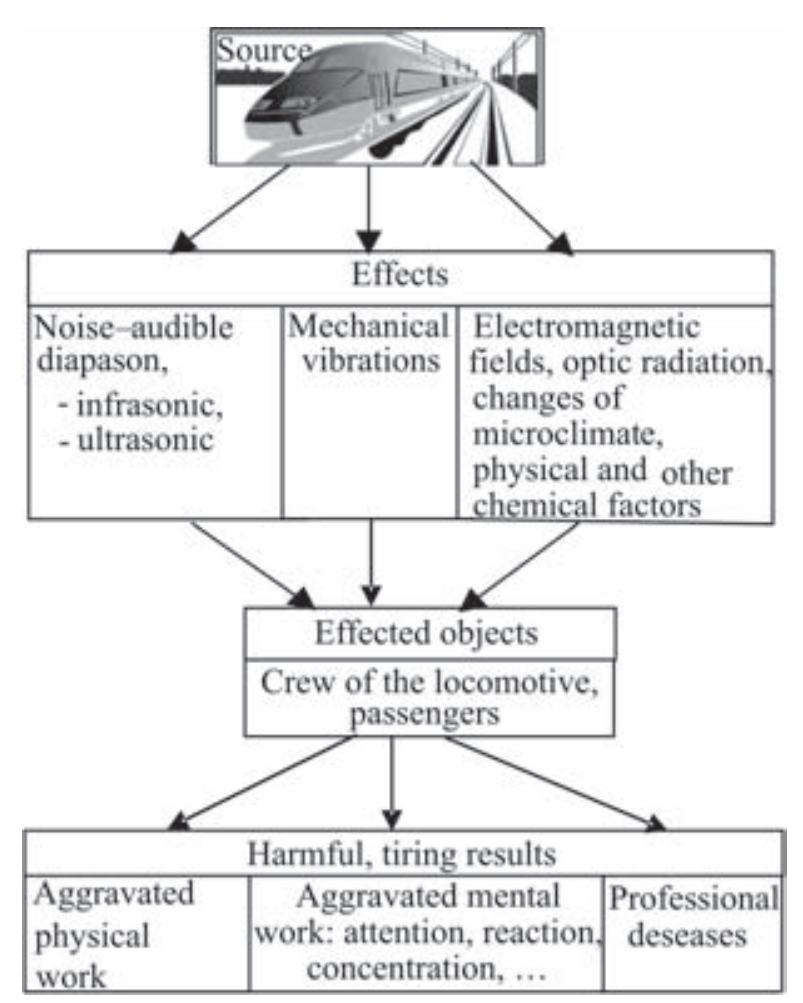

Fig 1. Scheme of harmful factors to human health

Table 1. Equivalent noise levels in a working place in railway transport

\begin{tabular}{|l|c|}
\hline \multicolumn{1}{|c|}{ Object } & $\begin{array}{c}\text { Equivalent } \\
\text { sound level, dB }\end{array}$ \\
\hline $\begin{array}{l}\text { Cabins of an operator in steam, diesel } \\
\text { locomotives }\end{array}$ & 80 \\
\hline $\begin{array}{l}\text { Cabins of an operator in suburban } \\
\text { electric locomotives }\end{array}$ & 75 \\
\hline $\begin{array}{l}\text { Rooms of personal in the wagons of the } \\
\text { distant communication trains }\end{array}$ & 60 \\
\hline $\begin{array}{l}\text { Service rooms in electric stations, } \\
\text { cooling sections }\end{array}$ & 60 \\
\hline $\begin{array}{l}\text { Service rooms in luggage and post } \\
\text { wagons }\end{array}$ & 70 \\
\hline $\begin{array}{l}\text { Relaxation rooms in luggage and post } \\
\text { wagons }\end{array}$ & 60 \\
\hline Service rooms in restaurant - wagons & 70 \\
\hline
\end{tabular}

II - the noise inside the control cabin. This is the noise caused by a speed meter, the engine driver's crane, the whistle and watchfulness signal.

III - the noise inside the machine section. The main source of the noise in the machine section is power aggregate - a diesel, also the noise caused by ventilators, reducers of auxiliary aggregates, the main electricity generator, the double machine aggregate, breaking compressor, the turbocompressor as well as the exhaust system of combustion products.
The axle-wheel noise is caused by the interaction between rail irregularities and the bandage rolling on the rail head surface as well as by the sliding of the wheel along the rail in longitudinal and cross directions. The vibrations of the bandage and the wheel centre can cause wideband spectrum noise level up to $120 \mathrm{~dB}$. The axle-wheel noise may be drowned by the gear noise when movement speeds are low and loads are big.

Rolling noise largely depends on the movement speed of the rolling-stock. Normally, the sound pressure rate increases by $9 \mathrm{~dB}$ with the double increase of speed. The wheel-caused noise may be different with regard to the type of the rolling-stock. The irregularities of interacting surfaces agitate vibrations of the wheel and the rail under the influence of the masses inherent in the movement. Vibrations of different amplitudes are agitated in them depending on the properties and geometrical forms of materials of the rail and wheel. The motion of these bodies' surfaces causes the vibrations of air particles, thus inducing ambient air noise.

The noise in railway transport facilities is measured by the procedure established by the following standard documents:

ISO 1996/1-1982 "Acoustics - measurement and noise description in ambience. Part I. The main parameters and measurement methods";

ISO 1996/2-1987 “Acoustics - measurement and noise description in ambience. Par II. Collection of data relevant to land usage";

ISO 1996/3-1987 “Acoustics - measurement and noise description in ambience. Part III. Application of noise limitation".

The general diagram can be conveniently represented by signal graphs as shown in Fig 2. The joints in the graph represent variable energy flows (sources), and the arcs represent the sound energy transmitting channels defined by the reduction indices of sound energy intensity [7-9].

Referring to the signal graph represented in Fig 2 sound power flow $J_{i s}$ in the analysed direction of the sound field of the rolling-stock is written as follows:

$$
J_{i s}=W_{1} C_{1}+W_{2} C_{2}+\ldots+W_{k} C_{k}=\sum_{i=1}^{i=k} W_{i} C_{i}
$$

$i=1,2,3 \ldots ., k$.

The intensity rate $L_{i s}$ by its numerical value equal to the sound pressure rate expressed in $\mathrm{dB}$ is written as follows:

$$
L_{i s}=10 \lg J_{i s} / J_{0}=10 \lg \sum_{i=1}^{i=k} W_{i} C_{i} / J_{0} \leq\left[L_{i s}\right]
$$

$W_{1}, W_{2}, \ldots, W_{k}$ are sound capacity of noise sources; 


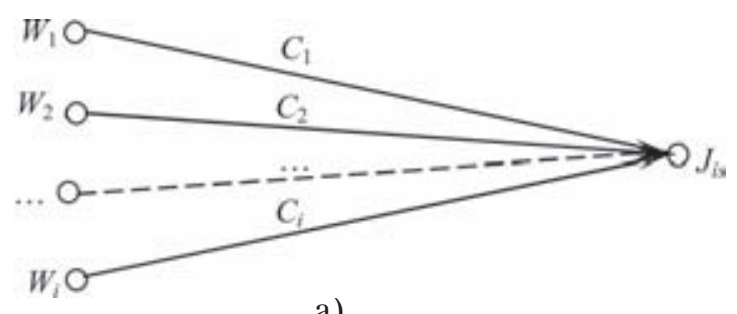

a)

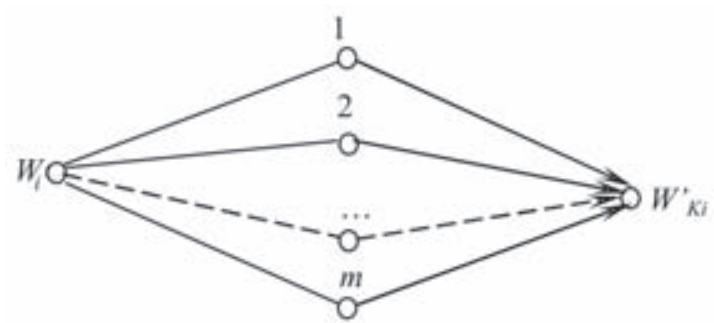

b)

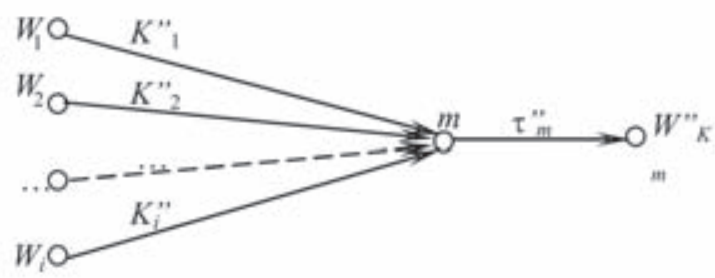

Fig 2. Signal graphs: a) Graph of external noise calculations b) and c) evaluation of internal noise inside the cabin of the locomotive

$C_{1}, C_{2}, \ldots, C_{k}$ are the indices involving intensity reduction with the increase of distance from the noise sources; $J_{0}$ is the limit value of sound intensity, $J_{0}=10^{-12} \mathrm{~W} / \mathrm{m}^{2} ;\left[L_{i s}\right]$ is the rate of permissible external noise.

Two ways for determining sound energy in the rolling-stock cabin are used (Fig 2 b and c): from each source via all elements of the cabin or from all sources via each element of the cabin. For the first version of calculation the sound energy in the cabin is expressed as follows:

$W_{K i}^{\prime}=W_{i}\left(K_{1}^{\prime} \tau_{1}^{\prime}+K_{2}^{\prime} \tau_{2}^{\prime}+\ldots+K_{m}^{\prime} \tau_{m}^{\prime}\right)=W_{i} \sum_{i=1}^{i=m} K_{m}^{\prime} \tau_{m}^{\prime}$

for the second version of calculation

$W_{K m}^{\prime \prime}=\left(W_{1} K_{1}^{\prime \prime}+W_{2} K_{2}^{\prime \prime}+\ldots+W_{k} K_{k}^{\prime \prime}\right) \tau_{m}^{\prime \prime}=\tau_{m}^{\prime \prime} \sum_{i=1}^{i=k} W_{k} K_{k}^{\prime \prime}$

$K_{1}^{\prime}, K_{2}^{\prime}, \ldots$ and $K_{1}^{\prime \prime}, K_{2}^{\prime \prime}, \ldots$ indices evaluating the transfer of sound energy to the surfaces of relevant partitions; $\tau_{1}^{\prime}, \tau_{2}^{\prime}, \ldots$ and $\tau_{1}^{\prime \prime}, \tau_{2}^{\prime \prime}, \ldots$ are the indices evaluating the transfer of sound energy through relevant partitions.
The number of signal graphs in the diagram being calculated is defined by the number of noise sources being evaluated, as well as by the number of elements homogeneous according to sound permeability in all surfaces of the cabin. The calculations are carried out according to the corrected and octave sound capacity values by evaluating relevant values of transfer indices $\tau$ - sound permeability partitions. Evaluating of the total sound intensity in the cabin will be

$$
J_{k}=\frac{\sum W_{k}}{\bar{\alpha} S_{\Sigma}},
$$

$\sum W_{K}$ is the total sound energy of the cabin calculated by the formula

$$
\sum W_{K}=\sum_{i=1}^{i} W_{K i}^{\prime}=\sum_{i=1}^{m} W_{K m}^{\prime \prime}
$$

$\bar{\alpha}$ is a medium sound absorption coefficient in the cabin and the body; $S_{\Sigma}$ is area of internal surface of the cabin and the body.

The noise rate (sound pressure ratio) in the cabin of the rolling-stock is calculated by the formula

$$
L_{K}=10 \lg \sum \frac{W_{K}}{\bar{\alpha} S_{\Sigma} J_{0}} \leq\left[L_{K}\right],
$$

$\left[L_{K}\right]$ is the allowed noise rate in the cabin.

Transmission indices $C_{i}$ evaluating the reduction of sound intensity with the increase of the distance from the point of the source are determined by the relationship

$$
C_{i}=\frac{1}{\Omega r_{i}^{2}},
$$

$r_{i}$ is the distance of $i$-the noise source to the field point of the cabin sound of the rolling stock in consideration; $\Omega=4 \pi-$ for spherical sound radiation, $\Omega=2 \pi-$ for semi - spherical sound radiation (semi - spherical sound radiation will be for $H \leq r_{i} / 3$, here $H$ is the agreed point source height above the road surface).

Transmission indices $K_{i}$ in the equations (3) and (4) are calculated by the formula

$$
K_{i}=\frac{S_{i}}{\Omega r_{i}^{2}},
$$

$S_{i}$ is surface area of the partition.

The index of sound energy transmission through the partitions (sound permeability coefficients) is calculated

$$
\tau_{i}=10^{-0.1 R_{i}}
$$

$R_{i}$ is sound isolation of the partition. 
The presented acoustic calculation model of rolling-stock cabin allows the evaluation of structural solutions and, in case of emergency, taking extra measures in the process of rolling-stock design.

\section{Methods of evaluation}

For the modelling of internal noise in the locomotive we used ANSYS software to create 2D model of internal space of the locomotive body. The geometry of the model consists of four different parts:

1.internal space of the front control cabin;

2.internal space of the back control cabin;

3. communicating tambours to the internal space of the machine section;

4.internal space of the machine sector which was divided into 4 areas, for convenience, forming the finite elements grid.

In ANSYS/Multiphysic software the problems of acoustics are solved on the basis of harmonic response analysis by providing the harmonic pressure agitation (sinus type) at some points of fluid structure and obtaining the pressure distribution in the fluid. By changing the agitation frequency, variable sound distribution in the interval of different frequencies is obtained.

The stages of harmonic acoustic analysis are as follows:

1. Formation of the model

2. Indication of limit conditions and acoustic loads as well as the solution of finite elements model

3. Review of the results

Limit conditions of the model and loads. Constructing the calculation diagram for the front locomotive, the planar structure of finite elements is used. All the structure was described by 2D finite elements FLUID29 designed for a specified acoustic analysis. These acoustic elements have the following degrees of freedom: displacements UX, UY and pressure PRES. For acoustic finite elements FLUID29 the following characteristics of the material are to be specified: air density DENS, sound velocity in the air SONC and damping index MU. Also, the real constant is to be indicated, i.e. the sound pressure value taken as a hearing limit $p_{0}=2 \cdot 10^{-5} \mathrm{~N} / \mathrm{m}^{2}$. On formation of the grid of finite elements (Fig 3 ) and tightening of linear displacements of the body walls, ceilings and floor junctions as well as in the interior body space (Fig 4) the interaction surfaces of the fluid and a solid structure are indicated.

They are the floor surfaces of the locomotive (loaded by outside noise caused by the axle-wheels rolling), as well as the agreed surfaces of a diesel and ventilator (Fig 5). On the surfaces of the model the interaction between vibrating structures and fluid particles occurs. Also, the acoustic load, i.e. the harmoniously varying pressure (Fig 6) corresponding to the

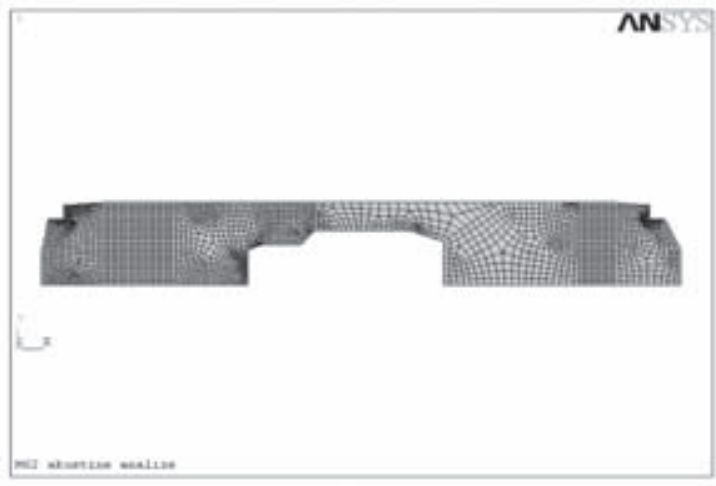

Fig 3. Final element grid of locomotive M62

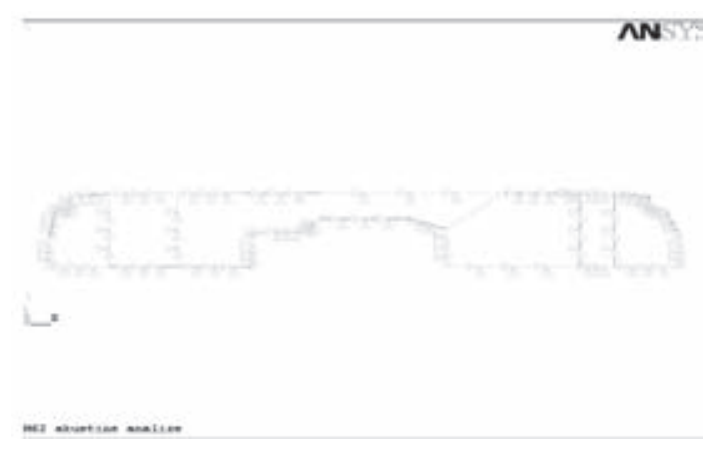

Fig 4. Boundary conditions of locomotive M62 model

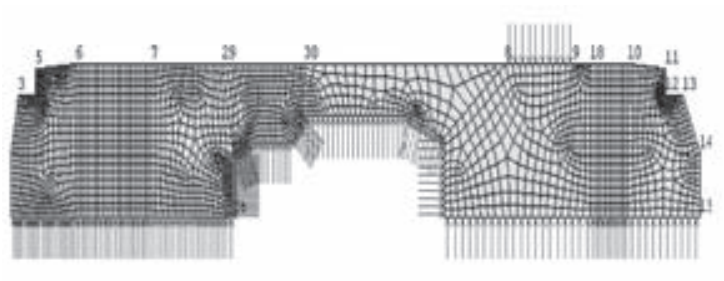

Fig 5. Excitation places of fluid of locomotive M62 model

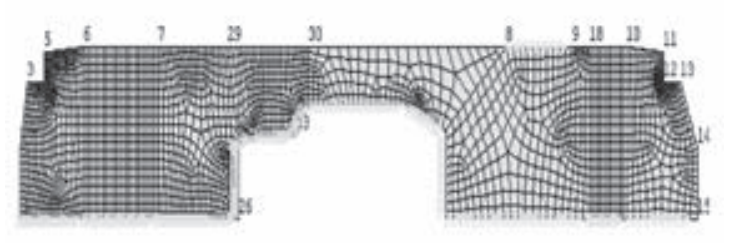

Fig 6. Acoustic loads of locomotive M62

sound pressure levels existing on these surfaces and represented in Table 2, is also indicated on these surfaces [7-9].

The solution of the model formed. Depending on the sound wave frequency, isolation materials as well as the interior elements damping characteristics vary as represented in Table 3 Therefore, the calculations are performed by varying the agitation frequency in 
Table 2. Sound pressure in various places of locomotive M62 [5]

\begin{tabular}{|l|c|c|}
\hline \multicolumn{1}{|c|}{ Surface } & Noise level, dB & Pressure, Pa \\
\hline $\begin{array}{l}\text { Floor of vehicle, } \\
\text { when speed } v,\end{array}$ & & \\
$\mathrm{~km} / \mathrm{h}:$ & & \\
30 & 90 & 0.632 \\
60 & 97 & 1.420 \\
90 & 103 & 2.830 \\
120 & 111 & 7.100 \\
\hline Engine & 120 & 20 \\
\hline Ventilator & 104 & 3.17 \\
\hline
\end{tabular}

terms of internal geometric frequencies of octave bands and by according changing of damping coefficients of the parameters defining sound energy damping surfaces of the model.

Side conditions of the model and conditions of load and solution. Forming the grid of finite elements and restricting linear displacements in the junctions of body walls, ceilings and floors as well as in internal space of the body, indicating the interaction surfaces of fluid and solid structure and by marking damping surfaces the model of finite elements of passenger locomotive shown in Fig 7, is obtained. The variations of damping parameters and loads are represented in Table 3 and 4.

The calculations are carried out changing the agitation frequency and damping parameters in an order analogical to the one presented in Table 4.

One of the essential indices of human comfort is the level of noise in his working and domestic environment. The permissible noise levels in thermal trucks according to OSZhD recommendations are the following [10-12]:

- $\quad$ long-term noise $-\mathrm{N} 80=80 \mathrm{~dB}$,

- $\quad$ interrupted noise $\mathrm{N} 85=85 \mathrm{~dB}$.

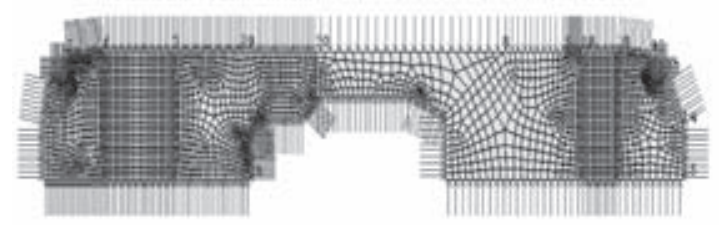

Fig 7. Energy damping surfaces of locomotive M62 model

Table 3. Sound pressure in various places of locomotive TEP60 [5]

\begin{tabular}{|l|c|c|}
\hline \multicolumn{1}{|c|}{ Surface } & Noise level, $\mathrm{dB}$ & Pressure, $\mathrm{Pa}$ \\
\hline $\begin{array}{l}\text { Floor of vehicle, } \\
\text { when speed } v, \\
\mathrm{~km} / \mathrm{h}:\end{array}$ & & \\
$\quad \leq 120$ & & \\
$\quad 120 \leq \mathrm{v} \leq 160$ & 105 & 1.260 \\
\hline Engine & 120 & 3.560 \\
\hline Ventilator & 109 & 20 \\
\hline
\end{tabular}

Table 4. Noise damping parameters [6]

\begin{tabular}{|c|c|c|}
\hline Frequency, $\mathrm{Hz}$ & Engine room & Cabin \\
\hline 31.5 & 63 & 125 \\
250 & 500 & 1000 \\
2000 & 4000 & 0.04 \\
0.04 & 0.04 & 0.04 \\
0.04 & 0.04 & 0.04 \\
0.04 & 0.17 & 0.17 \\
0.17 & 0.26 & 0.64 \\
0.89 & 0.75 & 0.78 \\
\hline
\end{tabular}

\section{Results}

Noise levels in control cabins of locomotives M62 and TEP60 are not equal driving at the maximal permissible speed $120 \mathrm{~km} / \mathrm{h}$ due to the difference of power $\left(\right.$ TEP60 $-N_{e}=2237 \mathrm{~kW}$, M62 $\left.-N_{e}=1421 \mathrm{~kW}\right)$ (Fig 8). Internal noise in the cabins of these locomotives exceeds the permissible values.

In Fig 9 there are shown changes of noise levels $L$ in the cabin of locomotive M62, when noise of the riding wheels increases. In the cabin the noise increases due to the increasing velocity of the train.

In Fig 10 the changes of noise inside the body of locomotive M62 are presented in the sound frequency range $125-1000 \mathrm{~Hz}$. In the machine section, where damping of sound waves is minimal, maximal sound pressure is formed and reaches $122 \mathrm{~dB}$. Such labour

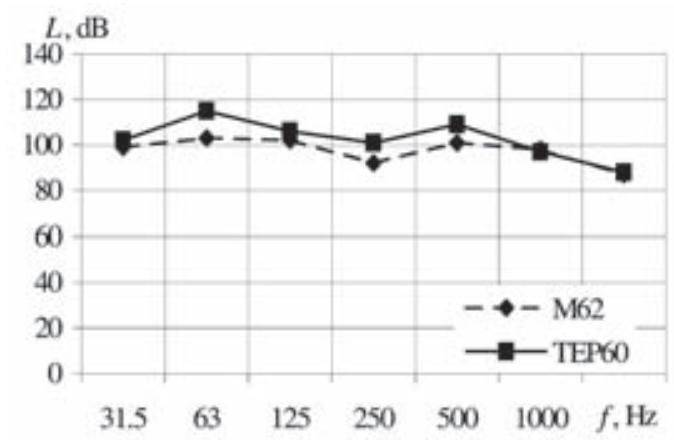

Fig 8. Comparison of noise levels in the cabins of M62 and TEP60 locomotives when velocity is $120 \mathrm{~km} / \mathrm{h}$

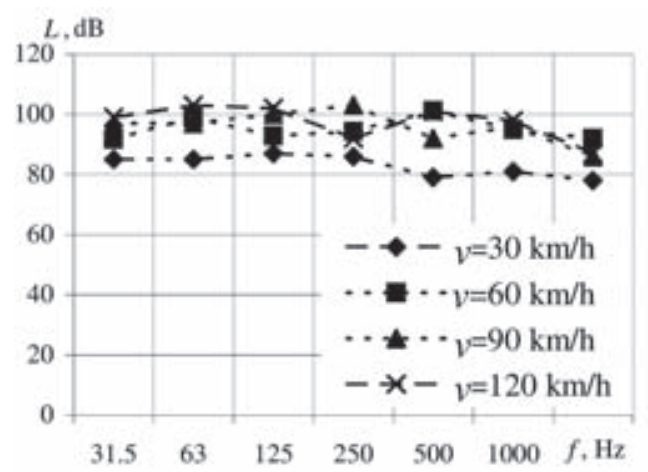

Fig 9. Changes of noise levels in the cabin of locomotive M62 driving at $30-120 \mathrm{~km} / \mathrm{h}$ speed 
environment is harmful for human health. Even the short time spent in such environment can cause the acoustic trauma. Noise spreading from the machine sector and external noise to the cabin is damped by the wall, floor and ceiling noise isolation. Noise level in all space of the operator's cabin is quite even and noise field is close to the diffusive noise filed.

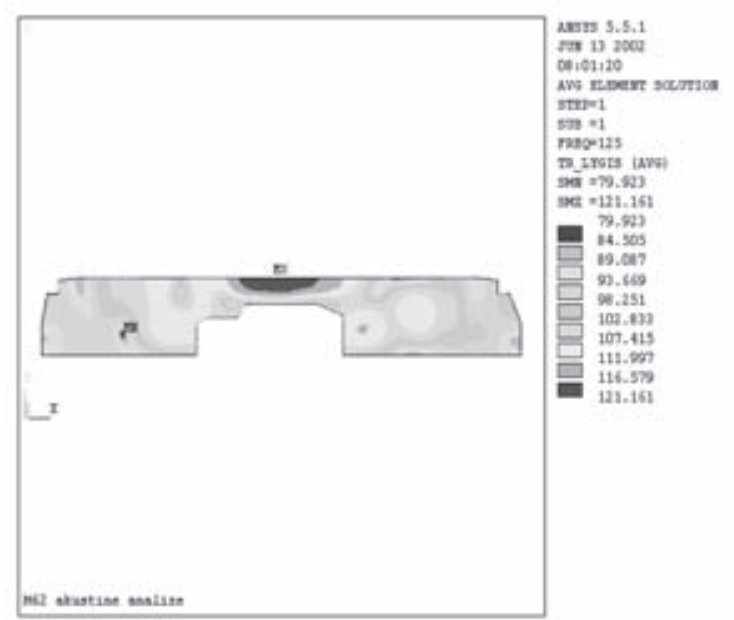

a)

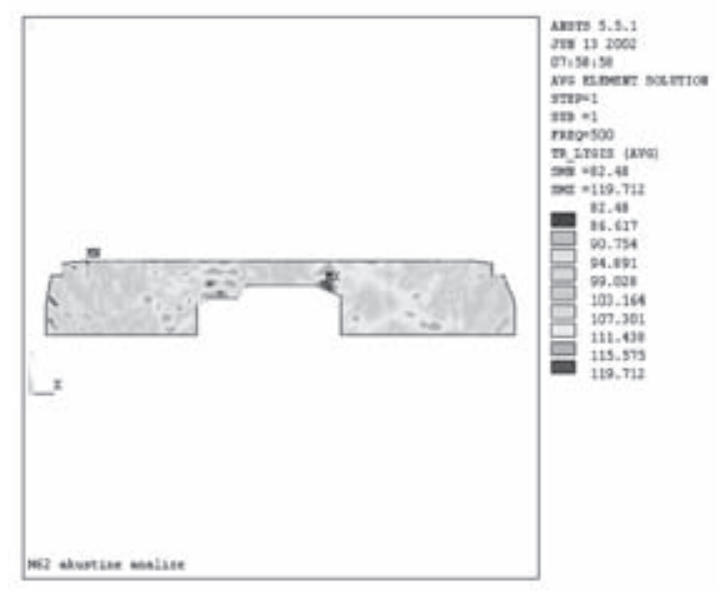

b)

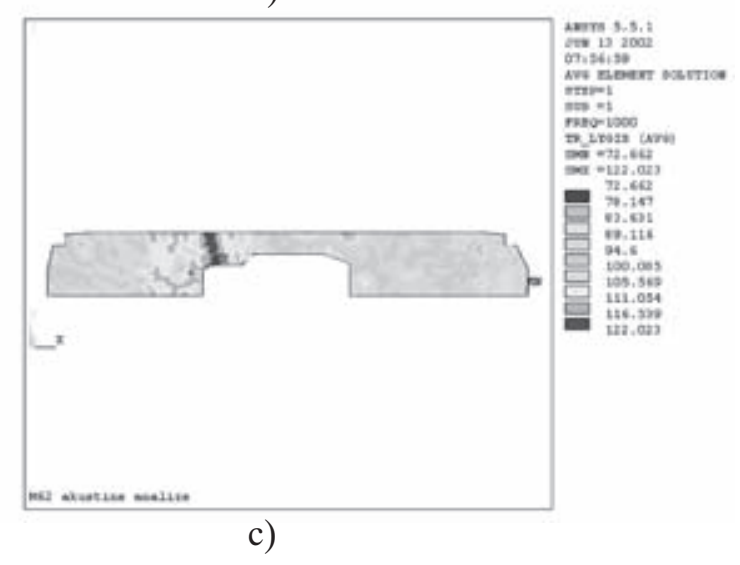

Fig 10. Changes of noise when excitation frequency: $\mathrm{a}-125 \mathrm{~Hz} ; \mathrm{b}-500 \mathrm{~Hz}$; $-1000 \mathrm{~Hz}$

\section{Conclusions}

1. Noise in high frequency ranges of the exploitated rolling stocks in Lithuania exceeds by $5 \mathrm{~dB}-$ $25 \mathrm{~dB}$ legislation norms. The main sources of noise pollution have a mechanical character the main and additional force agregates, road-wheel interaction, braking equipment, noise isolation equipment.

2. The highest noise level in a control cabin of passenger locomotive TEP60 is $106 \mathrm{~dB}$, locomotive M62 - $106 \mathrm{~dB}$ and in the machine section of locomotive TEP $60-120 \mathrm{~dB}$, the locomotive M60 - $125 \mathrm{~dB}$ in $31.5-250 \mathrm{~Hz}$ frequencies range of sound.

\section{References}

1. Steel, J. A. A study of engine noise transmission using statistical energy analysis. J. of Automobile Engineering, 1998, Vol. 212, part D, p. 205-213. ISSN 0954-4070.

2. A Study of European priorities and strategies for railway noise abatement, Final Report. 2002. 66 p.

3. Organization of cooperation in railway. Recomandations of influence of railway transport noise into environmental (Geležinkeliu bendradarbiavimo organizacija OSŽD. Geležinkelių transporto keliamo triukšmo poveikio aplinkai vertinimo rekomendacijos) Vilnius, 2001. 24 p.(in Lithuanian).

4. Baušys, R. Quality assessed solutions in acoustic analysis. Mechanika, 1999, No 1(16), p. 39-43.

5. Handbook of railway electro traction means, locomotives and disiel trains (Справочник по электроподвижному составу, тепловозам и дизель-поездам) Ed. by A. I. Tishchenko. Vol. II. Moscow: Transport, 1976. 376 p. (in Russian).

6. Acoustics. Handbook (Акустика: Справочник). Ed. by A. P. Jefimov, A. V. Nikonov, M. A. Sapozhkov, V. I. Shorov; Editor M. A. Sapozhkov. Moscow: Radio and comunication, 1989. 336 p. (in Russian).

7. Koo, D. H.; Kim, J. C.; Yoo, W. H.; Park, T.W. An experimental study of the effect of low-noise wheels in reducing noise and vibration. Transportation Reasearch, Part D 7, 2002, p. 429-439.

8. Bazaras, Z. Simulation of noise emission in the railway traction means. In: Proc. of the $11^{\text {th }}$ Int. Conf. on Urban Transport and the Environment in $21^{\text {st }}$ Century. Urban Transport, XI. WitPress Southampton, Boston, 2005, p. 521-530.

9. Steel, J. A. A study of engine noise transmission using statistical energy analysis. J. Automotive Engineering, 1998, Vol. 212, part D, p. 205-213. ISSN 0954-4070.

10. Hardy, A. E. J. Noise from railway bridges. J. Rail and Rapid Transit, 1999, Vol. 213, part. F, p. 161-172. ISSN 0954-4097.

11. Hardy, A. E. J. Railway passengers and noise. J. Rail and Rapid Transit, 1999, Vol. 213, part F, p. 173-180. ISSN 0954-4097,

12. Cervello, S.; Donzella, G.; Pola, A.; Scepi, M. Analysis and design of a low - noise railway wheel. J. Rail and Rapid Transit, 2001, Vol. 215, part F, p. 179-192. ISSN 0954-4097. 